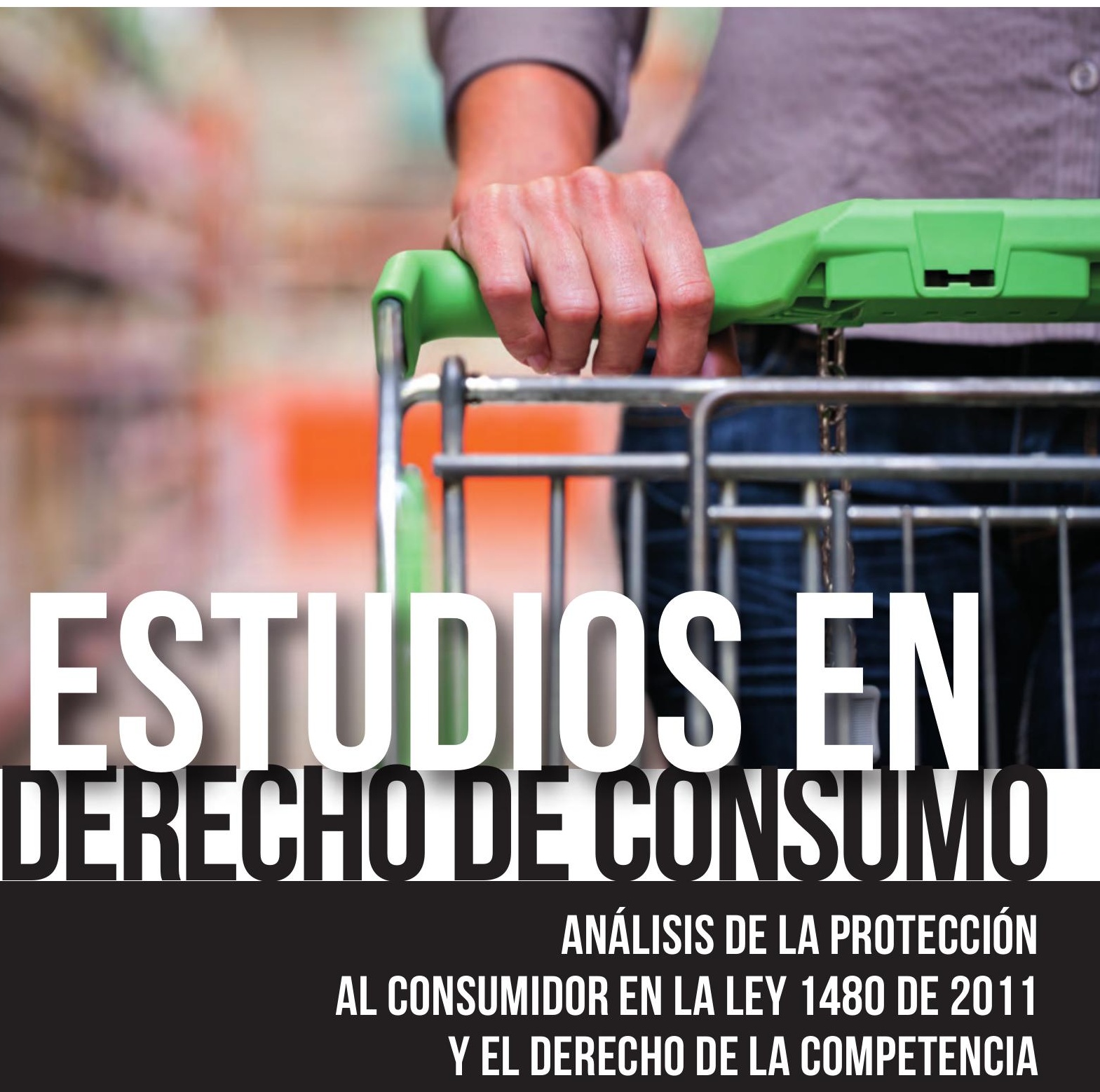

AUTORES

CARLOS ARTURO HERNÁNDEZ DÍAZ NOHORA ELENA PARDO POSADA PAOLA ANDREA ZULUAGA ORTIZ LEONARDO ACEVEDO VALENCIA 




\title{
ESTUDIOS EN DERECHO DE CONSUMO
}

\author{
ANÁlISIS DE LA PROTECCIÓN AL \\ CONSUMIDOR EN LA LEY I 480 DE 20 I I \\ Y EL DERECHO DE LA COMPETENCIA
}




\section{UNVERSIDAD LA GRAN COLOMBIA}

Fundador

Julio César García Valencia (I884-1959)

Presidente

José Galat Noumer

Rector

Santiago José Castro Agudelo

Vicerrector Académico

Rodrigo Lupercio Riaño Pineda

Vicerrectora Administrativa

María del Pilar Galat Chediak

Secretaria General

Marco Tulio Calderón Peñaloza

Decana Facultad de Derecho

Gloria Inés Quiceno Franco

Directora de Investigaciones

Beatriz Helena Robayo Castro
INSTITUCIÓN UNIVERSITARIA

POLITÉCNICO GRANCOLOMBIANO

Rectoría

Fernando Dávila Ladrón de Guevara

Vicerrectoría Académica

Jurgen Chiari Escobar

Vicerrectoría de Desarrollo Institucional

Javier Arango Pardo

Vicerrectoría de Estudiante

Alejandra Ordóñez Ospina

Vicerrectoria Administrativa y Financiera

Juan Camilo Pardo Acevedo

Secretaria General

Billy Escobar Pérez

Secretaria Académica

Sergio Hernández Muñoz

Facultad de Ciencias Sociales

Carlos Augusto García López 


\title{
ESTUDIOS EN \\ DERECHO DE CONSUMO
}

\author{
ANÁlisis DE LA PROTECCIÓN AL \\ CONSUMIDOR EN LA LEY I 480 DE 20 I I \\ Y EL DERECHO DE LA COMPETENCIA
}

\section{COMPILADORES}

María Alejandra lacayo Arana

Javier Francisco Franco Mongua

\section{AUTORES}

Carlos Arturo Hernández Díaz

Nohora Elena Pardo Posada

Paola Andrea Zuluaga Ortiz

Leonardo Acevedo Valencia 
Estudios en derecho de consumo

Análisis de la protección al consumidor en la ley 1480 de 2011

y el derecho de la competencia

Primera edición: Abril de 2018

ISBN: 978-958-8721-64-4

EISBN: 978-958-8721-66-8

EBOOK: 978-958-8721-65-1

Publicaciones Politécnico Grancolombiano

Eduardo Norman Acevedo

Lider de Publicaciones

Calle 57 \# 3-00 Este

PBX: 7455555 ext. 1171

E-mail: editorial@poligran.edu.co

Bogotá-Colombia

Dirección Editorial Universidad La Gran Colombia

Beatriz Helena Robayo Castro

Directora de Investigaciones

Calle 12C No. 5-15.

Teléfono: 2826386 ext: 188 - 232

E-mail: investigaciones.editorial@ugc.edu.co

direccion.investigaciones@ugc.edu.co

\section{Compiladores}

María Alejandra Lacayo Arana

Abogada

Javier Francisco Franco Mongua

Universidad La Gran Colombia

\section{Autores}

Carlos Arturo Hernández Díaz

Universidad La Gran Colombia

Nohora Elena Pardo Posada

Universidad La Gran Colombia

Paola Andrea Zuluaga Ortiz

Institución Universitaria Politécnico Grancolombiano

Leonardo Acevedo Valencia

Docente de la Universidad Libre

Analista de Producción Editorial

Paulo Mora Noguera

\section{Diseño y Armada Electrónica}

Huevofrito SAS

\section{Corrección de Estilo}

Gustavo Quesada

Impresión

Xpress Estudio Gráfico y Digital S.A.

Impreso en Colombia

Printed in Colombia

La editorial de la Institución Universitaria Politécnico Grancolombiano pertenece a la Asociación de Editoriales Universitarias de Colombia ASEUC.

"Las opiniones plasmadas en esta obra son de responsabilidad exclusiva de los autor, y no comprometen a las instituciones ni determinan su posición o filosofía institucional".

Ninguna parte de esta publicación puede ser reproducida, almacenada o trasmitida de manera alguna, ni por ningún medio, ya sea electrónico, químico, mecánico, óptico, de grabación o fotocopia, sin permiso escrito de la Institución Universitaria Politécnico Grancolombiano y de la Universidad La Gran Colombia.

\section{¿Como citar este libro?}

Lacayo-Arana et al. (2018), Estudios en derecho de consumo: Análisis de la protección al consumidor en la ley 1480 de 2011 y el derecho de la competencia, Bogotá: Publicaciones Politécnico Grancolombiano / Universidad La Gran Colombia. 


\section{ONTENIDO}

PRÓLOGO

I. INTRODUCCIÓN

II. EL PRINCIPIO DE LA AUTONOMÍA DE LA VOLUNTAD EN LOS CONTRATOS CON CONDICIONES GENERALES EN EL ORDENAMIENTO COLOMBIANO 45

1. Introducción $\quad 47$

1.1. Autonomía privada y condiciones generales de la contratación $\quad 54$

2. Protección a la autonomía privada en el derecho de consumo $\quad 59$

2.1. El control del contenido en los contratos de adhesión 61

2.2. El concepto de cláusula abusiva y cláusula prohibida 62

2.3. La lista de cláusula abusivas $\quad 64$

2.4. El control formal de las Condiciones Generales 66

2.5. La interpretación e integración de las Condiciones Generales $\quad 68$

3. Conclusiones $\quad 71$

III. LA RELACIÓN CONSUMIDOR, DISTRIBUIDOR Y PROVEEDOR BAJO EL ESTATUTO DEL CONSUMIDOR 77

1. Introducción $\quad 79$

2. El Estatuto del Consumidor y su armonización con el orden jurídico colombiano

2.1. Responsabilidad civil 83

2.2. Responsabilidad contractual 86

2.3. Responsabilidad extracontractual $\quad 87$

2.4. Antecedentes normativos de la Ley 1480

3. Las Contextualizaciones constitucionales del Decreto 3466 de 1982 y en el Estatuto del Consumidor 90

3.1. Contexto Constitucional del Decreto 3466

3.2. La constitucionalización del Derecho del Consumidor, Ley 1480 de 201191

3.3. Diferencias Conceptuales: Decreto 3466 de 1982 y Ley 1480 de 201192

3.3.1. Las Facultades de la Superintendencia de Industria y Comercio. $\quad 98$

4. El Concepto de Calidad en el Estatuto del Consumidor- Ley 1480 de 2011101 
IV. El USUARIO DE LOS SISTEMAS PIRAMIDALES: ¿CONSUMIDOR A PROTEGER O (IR) RACIONAL APROVECHADOR DEL ESTADO? 107

$\begin{array}{ll}1 . \text { Introducción } & 109\end{array}$

1.1. La racionalidad del inversor $\quad 111$

1.2. El caso Interbolsa $\quad 116$

1.3. El problema 118

2. De la racionalidad económico- jurídica de los individuos 119

3. Esquema ponzi o piramidal 122

3.1. Contribución a la exoneración de responsabilidad del Estado $\quad 128$

4. El usuario como inversionista 130

5. El usuario como consumidor $\quad 132$

6. Las consecuencias de la responsabilidad del Estado 136

7. Conclusiones 141

\section{LAS FACULTADES JURISDICCIONALES DE LA SIC EN EL MARCO}

DEL PRINCIPIO DE LA LEGALIDAD 151

1. Introducción 153

1.1. Protección de los consumidores: entre el mandato constitucional y la potestad de configuración del Legislador

2. La asignación de funciones jurisdiccionales a la SIC

2.1. Reglas constitucionales relativas a la atribución de funciones judiciales a las autoridades administrativas 160

2.2. Doctrina probable de la SIC. Razones para adoptar el precedente 161

2.2.1. Competencias Jurisdiccionales que cumple la SIC. En materia de protección al consumidor $\quad 165$

2.3. Garantías constitucionales en la acción jurisdiccional 203

3. Conclusiones 173

VI. LOS CARTELES DE EXPORTACIÓN Y SUS EFECTOS 177

1. Introducción 179

2. Efectos de los carteles dentro de un mercado de libre competencia 181

2.1. Los carteles como práctica restrictiva de la competencia 181

2.1.1. La existencia de un pacto 186

2.1.2. La independencia de los involucrados 188

2.1.3. El comportamiento voluntario, intencional y coordinado 190 
2.1.4. La inestabilidad potencial

2.1.5. Planeación anticipada e intencional de ventajas y desventajas $\quad 190$

2.1.6. Los carteles no tienen que producir efectos reales 191

2.1.7.Que la no competencia genere beneficios 192

3. Formas y clases de carteles 192

3.1. Sobre la fijación de precios $\quad 192$

3.2. Sobre la repartición de mercados 194

3.3. Sobre la asignación de cuotas 196

3.4. Los carteles de importación 196

3.5. Los carteles internacionales 197

3.6. Los carteles de exportación 198

4. Alcance de los carteles de exportación 199

5. Efectos de los carteles en un tratado de libre comercio 203

6. Conclusiones 206

VII. LA COLUSIÓN EN LA CONTRATACIÓN ESTATAL Y LA PROTECCIÓN DE LA

COMPETENCIA: RETOS DEL NUEVO SISTEMA DE COMPRAS PÚBLICAS EN COLOMBIA 213

1. Introducción 215

2. El marco legal y reglamentario aplicable a las conductas colusorias en el mercado de compras públicas en Colombia 219

3. Mecanismos establecidos en el EGCAP para evitar las prácticas colusorias 223

3.1. Aplicación del Régimen de inhabilidades 223

3.2. La exclusión de los oferentes coludidos o la declaratoria de desierta de los procesos de selección con ofertas producidas por acuerdos colusorios

4. Mecanismos para contrarrestar los efectos de las prácticas colusorias establecidas en el EGCAP

4.1. La acción de repetición $\quad 230$

4.2. La declaratoria de caducidad del contrato 232

5. La colusión y el proyecto de reforma al EGCAP presentado por

Colombia Compra Eficiente

6. Conclusiones 
